\title{
"There is No Single Right Answer": The Potential for Active Learning Classrooms to Facilitate Actively Open-minded Thinking
}

\author{
Victoria Chen \\ Queen's University
}

Education is meant to open your mind, but is that what universities are really doing? Rather than fostering open-minded thinking, the format of lecturing, the lack of interaction among students and instructors, and the passive nature of learning are likely producing the opposite, students with closedminds. The development and implementation of Active Learning Classrooms (ALC) has the capability to counteract this negative trend by providing a configuration suited for more collaborative learning and opportunities for students to share their thoughts, hear other perspectives from peers, and have the potential to become more open-minded. A description of a study on students in a fourth year psychology course is provided in which the instructor changed her course in order to use the ALC to its fullest capacity. Students were also given an Actively Open-minded Thinking questionnaire (Stanovich \& West, 1997) pre and post course, with results indicating that openminded thinking increased over the term. Although there are many components that could contribute to this result, the impact that educational spaces may have on student learning are discussed.

\section{Introduction}

$\mathrm{I}_{\mathrm{d}}^{\mathrm{n}} \mathrm{s}$ nstead of opening students' minds to inquire more deeply about course content, most courses elicit student questions such as "Will this be on the exam?" and "What is the right answer for the exam?" Admittedly, during my undergraduate years all I wanted to know was whether the question would be on the exam and what answer was required to receive full marks. My curiosity for learning was absent, all non-exam information was ignored, and my main goal in class was to find the "correct answers" in order to achieve an $\mathrm{A}$ on the exam. This way of thinking could have been primarily due to the assessment format in most of my courses which typically were
200 item multiple choice questions; gaining a richer conceptual understanding did not provide an immediate dividend. But secondly, and perhaps more importantly, my mentality for learning was rooted in the lack of interaction and discussion I had with my instructor and fellow students.

It was clear from day one that when the instructor stated, "No questions are stupid, please ask," any student who interrupted the class to ask a question stopped the flow of the lecture resulting in frustration for the other students in the room. At the same time, you could not pose questions to your peers during class because the instructor would chastise you 
for talking in class. The lecture hall was designed as a space to listen to one person at the front of the room, not an appropriate place to have interactive conversations or ask off topic questions. Is this really the ideal environment for learning?

The literature on learning spaces suggests that the answer is no. Lecture halls create a physical and emotional hierarchical barrier between the instructor and students, and among students themselves (Baepler \& Walker, 2014). The location of the instructor's podium conveys the status of the instructor as the all-knowing leader and sole expert in the room, with students' roles limited to listener rather than participant with valid contributions to learning. The format limits student to student interaction, and makes instructor to student interaction impersonal and disengaging (Baepler \& Walker, 2014). Without interpersonal interactions and exposure to multiple perspectives, I suspect students are less likely to consider different perspectives on a topic or an argument. For example, Toplak and Stanovich (2003) found that fourth-year students listed significantly fewer arguments against a position they held compared to students in first-year, suggesting students were possibly becoming less open-minded over the course of their undergraduate degree.

Employers have also noticed this trend in seeing graduates with an increasingly limited and narrow frame of mind over the last decade (Vedder, Denhart, \& Robe, 2013). In a recent survey in 2013, employers stated universities are producing too many graduates who lack the ability to be open to new ideas, to modify and question assumptions, critically think, and be innovative (Hart Research Associates, 2013). The snowballing effect of universities limiting opportunities for students to be open-minded to graduates having difficulty finding a job does not necessarily have a direct causal relationship, but in my experience could be a contributing factor if all learning experiences in university are restrictive in this manner.

One way to disrupt the default lecturing style is to change the physical space of the learning environment (Beichner, 2014; Brooks, 2012). When I began research on newly implemented Active
Learning Classrooms (ALC) on campus, I saw a vastly different space from my undergraduate studies (see Figure 1). Instead of rows of seating, students sat in groups, were expected to talk to each other, and encouraged to share ideas with peers within and outside the group. The classroom lacked an identifiable front and was thus no longer a structured hierarchy. The spotlight was not on the instructor teaching, but rather on the students, their learning and perspectives.

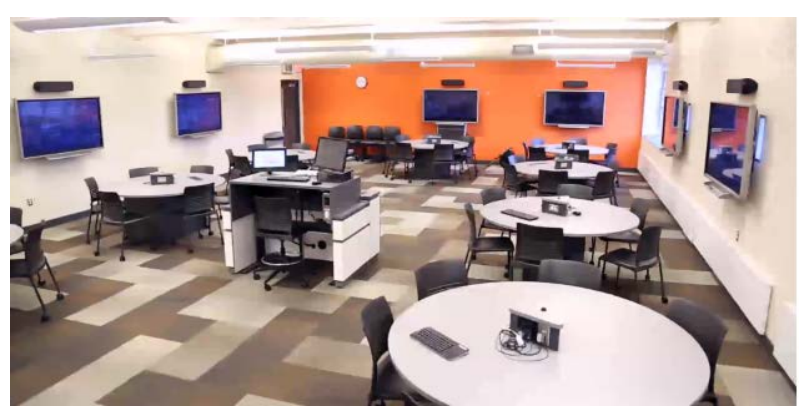

Figure 1

\section{Active learning classroom (ALC)}

The initial drive to create ALCs was to provide advanced technologies and spatial configurations needed for science courses such as physics and engineering, giving instructors a seamless transition between lecturing and laboratory work within a single space (Beichner, 2014). Since then, ALCs have been used by other disciplines that could also benefit from the spatial configuration and interactive technology while still accommodating large course enrolments (Horne, et al., 2014). Studies on these new learning environments have shown vast improvements in student engagement and attendance compared to traditional classrooms (Walker, Brooks, \& Baepler, 2011). Both students and instructors reported being more enthusiastic about learning and teaching in these environments (Thaman, Dhillon, Saggar, Gupta, \& Kaur, 2013); instructors were more likely to incorporate active learning strategies into their courses (Oblinger 2006; Walker, Brooks, \& Baepler, 2011). Active learning has been shown to increase content knowledge, critical thinking, and problem-solving abilities relative to results with 
traditional lecture teaching strategies (McCarthy \& Anderson, 2000). Active learning strategies gradually develop students' adaptability, communication, and interpersonal skills (Kember \& Leung, 2005).

\section{Space Influencing Course Design}

I became very intrigued by the concept of the learning space influencing instructors' course design, and considered how an instructor who wanted to increase open-minded thinking among students could do so in an ALC. Upon interviewing all the instructors scheduled to teach in the ALCs, I encountered one instructor who expressed interest in completely redesigning her fourth-year psychology course in order to implement active learning techniques she could not otherwise do in a traditional lecture hall. She explained the difficulty in getting students to work in groups when seated in a lecture hall. Students were often resistant to turning around to face fellow students to form groups, or complained about moving all their belongings across the row to sit with other students to form a group. The simple task of forming groups consumes significant time during a class. In addition, she had always wanted to incorporate debates into a course but found it hard for students to hear or see each other across the lecture hall, thereby making the debates ineffective. She admitted this would be a significant departure from her normal lecture style of teaching in which she had complete control of the delivery of content and pace of the lecture.

A month later, I met with the instructor to see her newly designed course syllabus. The course syllabus outlined several activities that would take place throughout this course: class debates; student lectures; writing individual papers; developing as a group a Wikipedia entry on modern psychology; preparing exam questions as a group; and group discussions on controversial psychology topics. The aim was for students to develop a deep understanding of the complex nature of modern psychology, how there were several different movements, the cause and consequence of the movements, and how there were no single "right" answers.

This led me to conduct the current study in which I examined whether an active learning environment and pedagogy would increase students' open-mindedness over a single term. Data were gathered using Stanovich and West's (2007) Actively Open-minded Thinking (AOT) Questionnaire (available upon request from the authors) and from conversations between students and the instructor throughout the term this research was conducted. This research project was approved by the Human Research Ethics Board of Queen's University.

\section{Participants}

All 40 students in this class were fourth-year psychology majors; 28 participated in the study. According to the instructor, this was the first course most students were taking that had a strong emphasis on group work. In most first to third-year psychology courses, class sizes are much larger with little to no group work. Participation in this study was on a voluntary basis with no monetary compensation. Students were told their participation would contribute to the development of how these classrooms were used for teaching future classes.

\section{Actively open-minded thinking (AOT) questionnaire}

The AOT questionnaire by Stanovich and West (1997) is composed of multiple subcategories including: flexible thinking, openness to ideas, openness to values, absolutism, dogmatism, and categorical thinking, which together provide a measurement for open-minded thinking. Actively Open-minded Thinking is generally defined as a person's ability to actively reflect on his/her thinking, actively seek and process information that contradicts his/her beliefs, and be willing to alter his/her mindset after carefully considering opposing beliefs 
(Stanovich \& West, 1997; 2007; Toplak, West, \& Stanovich, 2012). Previous studies have shown that students with higher AOT scores are better able to contextualize prior knowledge and personal beliefs in order to make rational decisions (Stanovich \& West, 2007).

The questionnaire was administered online using Fluid Survey outside of class time to limit disruptions to class sessions. The instructor posted the link to the questionnaire through the course website during the first week of class and again one week following the end of the class. Participants rated their agreement to 41 statements such as, "Right and wrong never change", "I believe letting students hear controversial speakers can only confuse and mislead them," "Changing your mind is a sign of weakness," "No one can talk me out of something I know is right," and "I have a lot of intellectual curiosity" on a scale of 1 - Disagree Strongly to 6 - Agree Strongly. The 41 -items are treated as a single scale (i.e., a subscale is not calculated). The typical mean AOT scores from samples of university students in previous studies have ranged from 168 to 170 ( $S D=18.2-18.3$ ) (Sá, West \& Stanovich, 1999; 2005; Stanovich \& West, $1997,2007)$. The scale has a minimum score of 41 , and a maximum score of 246.

\section{Findings}

The mean of the sample was 184.96 and the standard deviation was 26.28. The scores were normally distributed, and the Cronbach's Alpha was 0.84. Nine of the original 28 students completed the postAOT (low response rate is discussed in the limitation section). In order to continue analyses, a MannWhitney $U$ test was used to compare the pre-test score for the nine students to the pre-test scores of the original 28 pre-test scores to ensure the nine students were not different from the rest of the students. The results showed the sample of nine was not significantly different from the pre-test sample.

A paired samples t-test demonstrated postAOT scores $(M=190.44, S D=23.13)$ were significantly higher than the pre- AOT scores $(M=$ $184.44, S D=25.87), t(8)=2.67, p=0.03$ suggesting
AOT improved over the term. The effect size was calculated to measure the strength of the relationship between the two variables using Cohen's $d$ (1988). The effect size was $d=1.89$ and is considered large suggesting a strong relationship despite the small sample size.

Pre-AOT scores were divided into two categories, high pre-AOT (above the sample's mean AOT, $N=5$ ) and low pre-AOT (below the sample's mean AOT, $N=4$ ) to determine the nature of the increase in AOT. The results showed students with low pre-AOT had a greater increase in AOT $(M=$ $12.25, S D=6.39)$ over the course of one term than students with high pre-AOT, $(M=1.60, S D=3.36)$, $t(7)=3.24, p=0.01$. The interpretation of these results needs to be cautious because the groups were very small. However, on the basis of the difference in mean, there is an apparent increase in AOT from pretest to post-test especially for those with low preAOT. The lack of significant change in high preAOT could be attributed to a ceiling effect (Cramer $\&$ Howitt, 2004) in scores because the high pre-AOT scores were already getting close to the maximum. See Figure 2 for depiction of findings.

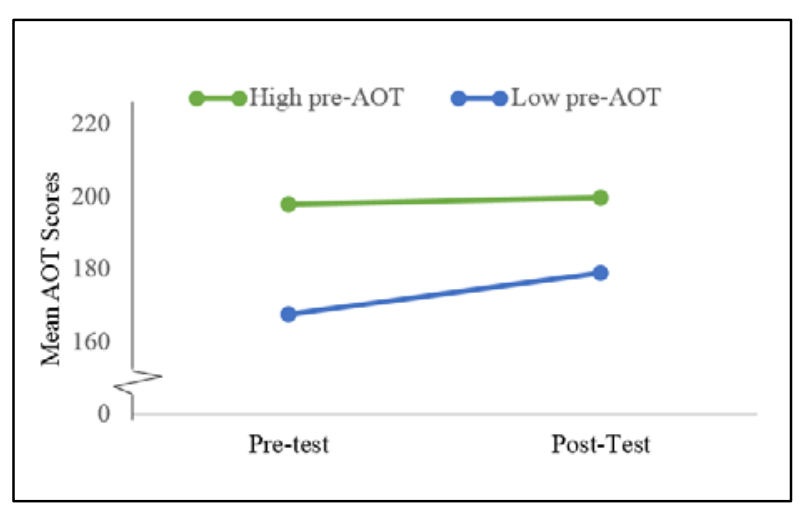

Figure 2

\section{Graph of mean pre and post AOT scores}

The informal conversations I had with students during class breaks provide some further evidence to strengthen the AOT results. Repeatedly, students emphasized their excitement for the course 
throughout the term. As one student stated, "I believe that the course in the active learning classroom did facilitate discussions and the sharing of information between students, as well as with the instructor." Another student said, "I liked that a lot of the course was discussion based - I wasn't just passively sitting and taking notes mindlessly." I asked students to think about how the course and space allowed them to see other students' perspectives on topics and whether this was different from courses in other rooms. The common answer was simply there were no discussions or conversations in other courses in their program, and they were mostly lecture based with individual assignments. Some students did however compare their experience to experiences in other disciplines that did have more discussions.

"Being able to see everyone in my table group made a huge difference for me to express my thoughts and to understand their thoughts compared to doing the same thing in a lecture hall."

"The screens around the room helped me see what other groups were talking about and I was able to see so many different opinions on the same topic."

"I liked that there were no right or wrong answers for the assignments but instead pushed us to look at issues on both sides."

"I liked the challenge in this course and hearing other students' thoughts on the topics often made me rethink my position."

"I was very impressed with how relaxed it felt, and therefore created an environment for collaboration and authentic discussion. There wasn't a pressure to get the answers right. I was more comfortable sharing my thoughts and understanding where other students were coming from."

On the other hand, a few students mentioned they found it hard to balance between being completely open-minded to ideas from their peers and wanting the instructor to provide more direct information to them by confirming the "right" answer. As one student stated "I would have benefitted from the professor synthesizing the material and addressing the important point for each chapter and telling us what we needed to know for the exam." Another student agreed with this student, "It would have been easier taking a course with just multiple choice exams [than working and coordinating with peers on activities], but this is something that we will have to deal with in the real world as well so it is a good learning opportunity."

As for the instructor, she was surprised by how well the group format worked and enjoyed adopting the facilitator over the lecturer role. Having taught many years in the psychology department, she did not expect students to have so many different perspectives and have the ability to engage in the material to such a great extent. She enjoyed having both casual and formal conversations with students throughout the class and becoming better acquainted with students on a more personal level than in any previous course she had taught. Although there were logistic problems such as coordinating group activities, becoming accustomed to the technology, and learning how to efficiently move around in the space, she was very pleased with the space. "I learned a lot about what students are capable of by being in this space, and I will be including many activities in this course in my future courses."

\section{Limitations and Challenges}

It is difficult to conclude whether the course and/or learning space led to an increase in AOT without a control group. However, there were no appropriate control groups in other courses in the program that would have produced meaningful comparisons. Although courses outside the department could have acted as control groups, the issue of difference in content and teaching and learning traditions would have confounded any possible analysis. The course is also not offered every year, and comparing this course to a course in a subsequent year or two would similarly not be meaningful.

The problem of the low participation in post-tests may be due to a couple of issues. First, the post-test was administered after the end of the term with the intention of capturing the entirety of students' course experience. However, this placed the post-test during the exam period. Students participating in the study were preparing for the 
course's final exam. In addition, more than half of the students in the class were also defending their undergraduate theses that week. Thus, it was not a convenient time for students to complete the questionnaire. Second, after the students did the pretest, many students stated the questionnaire was far too long and cumbersome to complete on their own time (approximately 8 minutes). This could not be changed because removing questions would cause the scores to be invalid and eliminate crucial components of the AOT concept. It is likely the length of the questionnaire may have contributed to students' reluctance to complete it during their busy schedule. Third, the link to the post-test was posted on their course website, and it is unclear how many students checked the course's website after the end of term. In hindsight, the questionnaire likely would have had a better post-test response rate if it was completed in class as time seemed to be the main issue for students. For current studies on ALCs, I have asked instructors to administer questionnaires or surveys at the beginning of a class or during break time. This has produced a much higher response rate for our current investigations.

\section{Conclusions}

Despite the limitations, this study is an example of how a space may impact an instructor's course design and teaching strategies in ways that have the potential to influence students' open-mindedness. Figure 3 provides a visual illustration of this relationship. The space alone would not lead to open-mindedness if the implemented pedagogy did not align with this goal. The new learning space offers opportunities for students to communicate their ideas to the peers in their group (round tables and screen) and to the entire class (circular configuration of tables around the room and screens on the walls). But an instructor needs to take advantage of this potential and incorporate appropriate activities which develop the capabilities of the spatial configuration and technology. Many instructors likely do the same activities in a standard lecture hall as were used in the course studied here, but the instructor in this study was reluctant to do so in traditional spaces and saw physical and technological barriers that would prevent her from implementing these activities. The space changed the instructor's perception of what could be achieved in her course which in turn had the potential to influence students' learning and openmindedness.

Although only a small sample of students completed the post-AOT questionnaire, the findings do suggest students can become more open-minded over a semester when a course is delivered in an ALC. As Figure 2 illustrated, the greatest increase in openmindedness was observed in students with lower pretest scores than students with higher pre-test scores. The informal conversations with students provide some evidence to strengthen the suggested change in AOT over the semester. Students stated the spatial

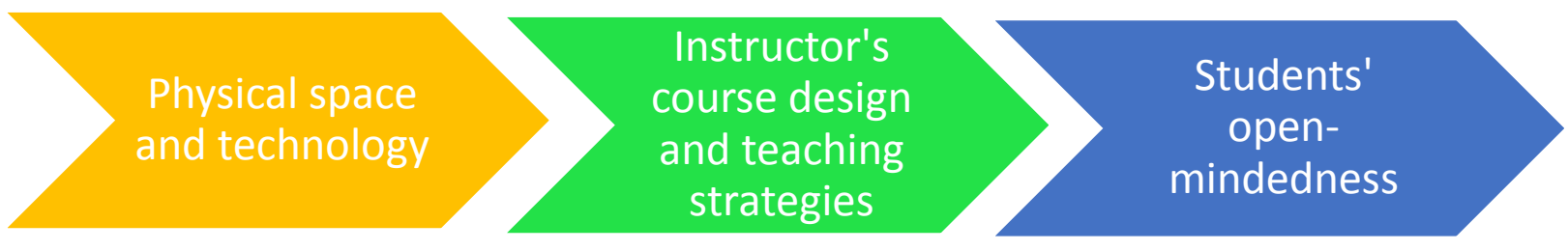

Figure 3

From physical space to open-minded thinking 
configuration and technology allowed them to more effectively communicate within the group, see what other groups were doing, and share ideas. As a consequence, students reported feeling more comfortable in this room, and learned more by considering and understanding different perspectives. Furthermore, students believed the pedagogy used by the instructor deemphasized the sense of competition among the students and promoted a more relaxed yet intellectually challenging learning environment. This provides hope against the trend found by Toplak and Stanovich (2003) of fourth-year students being less open-minded than first-year students, as this group of students stated they were opened to other students' perspectives which in some cases contributed to changing their own opinions.

\section{Implications}

This study suggests that instructors need to consider the learning opportunities that could occur in their particular teaching space. In an ALC where the focus is on the students instead of the instructor, learning outcomes that may not have been possible or easy to accomplish in a traditional lecture hall may be considered. In this study, the focus was on the potential for students to increase their open-minded thinking, but many other cognitive thinking skills may also be considered.

After considering what learning activities and lessons are possible in a particular teaching space, instructors need to keep in mind that not all students may be comfortable with a learner-centered pedagogy on the first day of class. In this study, a few students mentioned slight issues specifically with the completely learner-centered pedagogy. They wanted more direct instruction from the teacher or for information to be confirmed by the teacher, and not discussed solely with peers. More students may have felt this way as well as suggested by Kain (2003), but did not express it to me or the instructor in this study. It would be naïve to assume all the students completely embraced the learner-centered pedagogy or that future groups of students would embrace this approach, thus instructors are well-advised to develop a balance between teacher-centered and studentcentered activities dependent upon the specific instructional context. As the instructor in this study admitted, she was a bit unsure of how the course would proceed and was worried about the reactions of students despite all the planning and preparing she had done. Overall, students embraced the change in space and pedagogy and found it different but refreshing. It is easy to be consumed in the negative experiences reported by students. Several students jokingly said to me at the end of the study that they wished they were not graduating so they could take another course in this space. Taking a fifth year is probably not worth the additional experience in this classroom, but the comments do show how much students enjoyed learning in the ALC.

Just as there are no single "right" answers in the real world, there is no single "right" way to use the ALC. Every group of students creates a different dynamic, every subject is structured differently, and every instructor has their own comfort zone when it comes to balancing lecturing and facilitating. However, taking the step forward in fostering more open-minded students will lead to graduates that will be better prepared to take on the real world and all its complexities.

\section{References}

Baepler, P., \& Walker, J. D. (2014). Active learning classrooms and educational alliances: changing relationships to improve learning. New Directions for Teaching and Learning, 2014(137), 27-40. http://dx.doi. org/10.1002/tl.20083

Beichner, R. J. (2014). History and evolution of active learning spaces. New Directions for Teaching and Learning, 2014(137), 9-16. http://dx.doi.org/10.1002/tl.20081

Brooks, D. C. (2012). Space and consequences: The impact of different formal learning spaces on 
instructor and student behavior. Journal of Learning Spaces, 1(2), 1-16.

Cohen, J. (1988). Statistical power analysis for the behavioral sciences $\left(2^{\text {nd }}\right.$ ed.). Hillsdale, NJ: Lawrence Erlbaum.

Cramer, D., \& Howitt, D. L. (2004). The Sage dictionary of statistics: a practical resource for students in the social sciences. London: Sage.

Hart Research Associates. (2013). It takes more than a major: employer priorities for college learning, the full report of the latest employer survey conducted for AAC\&U. Liberal Education, 99(2), 22-29. Retrieved from http://www.aacu.org/leap/public_opin ion_research.cfm

Horne, S., Murniati, C. T., Saichaie, K., Jesse, M., Florman, J. C., \& Ingram, B. F. (2014). Using qualitative research to assess teaching and learning in technology-infused TILE classrooms. New Directions for Teaching and Learning, 2014(137), 17-26. http://dx.doi. org/10.1002/tl.20082

Kain, D. J. (2003). Teacher-centered versus studentcentered: Balancing constraint and theory in the composition classroom. Pedagogy, 3, 104-108. http://dx.doi.org/10.1215/1531 4200-3-1-104

Kember, D., \& Leung, D. Y. (2005). The influence of the teaching and learning environment on the development of generic capabilities needed for a knowledge-based society. Learning Environments Research, 8, 245-266. http://dx.doi.org/10.1007/s10984 $-005-1566-5$

McCarthy, J. P., \& Anderson, L. (2000). Active learning techniques versus traditional teaching styles: Two experiments from history and political science. Innovative Higher Education, 24, 279-294.
http://dx.doi.org/10.1023/B:IHIE.0000047 415.48495 .05

Oblinger, D. (2006). Space as a change agent. In D. Oblinger (Ed.), Learning spaces, (pp. 1.11.4). Washington, DC: EDUCAUSE. Retrieved from http://www.educause.edu/ research-and-publications/books/learningspaces

Sá, W., Kelley, C., Ho, C., \& Stanovich, K. E. (2005). Thinking about personal theories: Individual differences in the coordination of theory and evidence. Personality and Individual Differences, 38, 1149-1161. http://dx.doi.org/10.1016/j.paid.2004.07.0 12

Sá, W. C., West, R. F., \& Stanovich, K. E. (1999). The domain specificity and generality of belief bias: Searching for a generalizable critical thinking skill. Journal of Educational Psychology, 91, 497-510. http://dx.doi. org/10.1037/0022-0663.91.3.497

Stanovich, K. E., \& West, R. F. (1997). Reasoning independently of prior belief and individual differences in actively open-minded thinking. Journal of Educational Psychology, 89, 342-57. http://dx.doi.org/10. 1037//0022-0663.89.2.342

Stanovich, K. E., \& West, R. F. (2007). Natural myside bias is independent of cognitive ability. Thinking \& Reasoning, 13, 225-247. http://dx.doi.org/10.1080/1354678060078 0796

Toplak, M. E., \& Stanovich, K. E. (2003). Associations between myside bias on an informal reasoning task and amount of postsecondary education. Applied Cognitive Psychology, 17, 851-860. http://dx.doi.org /10.1002/acp.915 
Toplak, M. E., West, R. P., \& Stanovich, K. E. (2012). Education for rational thought. In J. R. Kirby \& M. J. Lawson (Eds.), Enhancing the quality of Learning: Dispositions, instruction, and learning processes, (pp. 51-73). UK: Cambridge University Press.

Thaman, R. G., Dhillon, S. K., Saggar, S., Gupta, M. P., \& Kaur, H. (2013). Promoting active learning in respiratory physiology-positive student perception and improved outcomes. National Journal of Physiology, Pharmacy and Pharmacology, 3, 27-34. http://dx.doi.org/10.5455/njppp.2013.3.27 000

Vedder, R., Denhart, C., \& Robe, J. (2013). Why are recent college graduates underemployed? University Enrollments and Labor-Market Realities. Center for College Affordability and Productivity (NJ1). Retrieved from http://centerforcollegeaffordability.org/uplo ads/Underemployed\%20Report\%202.pdf

Walker, J. D., Brooks, D. C., \& Baepler, P. (2011). Pedagogy and space: Empirical research on new learning environments. EDUCAUSE Quarterly, 34(4). http://www.educause.edu/ ero/article/pedagogy-and-space-empiricalresearch-new-learning-environments

\section{Acknowledgements}

Dr. Andy Leger at the Queen's University Centre for Teaching and Learning provided assistance in planning and overseeing all the research projects conducted on the Active Learning Classrooms. This work was supported by the generous Alumni donations for the development and research of the Active Learning Classrooms.

\section{Biography}

Victoria Chen is a $\mathrm{PhD}$ candidate in the Faculty of Education at Queen's University and an Educational Development Associate at the Centre for Teaching and Learning. Currently, she holds a Doctoral SSHRC for her research examining how Active Learning Classrooms can be authentic learning environments, which allow students to connect information learned in their courses to life after university and develop essential skills for employment (e.g., communication skills, presentation skills, analytical skills, etc.). 


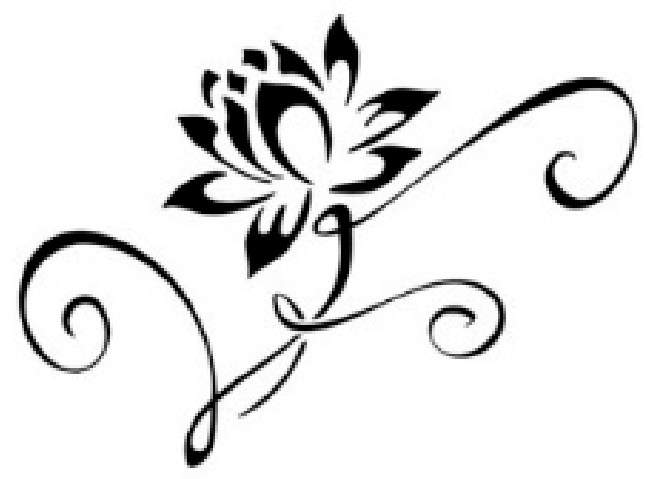

